\title{
Thin Film Electrodes for Anodic Stripping Voltammetry: A Mini-Review
}

\author{
Bryan R. Wygant and Timothy N. Lambert* \\ Sandia National Laboratories, Albuquerque, NM, United States
}

Anodic stripping voltammetry (ASV) is a powerful electrochemical analytical technique that allows for the detection and quantification of a variety of metal ion species at very low concentrations in aqueous media. While early, traditional ASV measurements relied on macroscopic electrodes like Hg drop electrodes to provide surfaces suitable for plating/ stripping, more recent work on the technique has replaced these electrodes with thin film metal electrodes generated in situ. Such electrodes are plated alongside the analyte species onto the surface of a primary electrode, producing a composite metal electrode from which the analyte(s) can then be stripped, identified, and quantified. In this minireview, we will explore the development and use of these unique electrodes in a variety of different applications. A number of metals (e.g., $\mathrm{Hg}, \mathrm{Bi}, \mathrm{Sn}$, etc.) have shown promise as thin film ASV electrodes in both acidic and alkaline media, and frequently multiple metals in addition to the analyte of interest are deposited together to optimize the plating/stripping behavior, improving sensitivity. Due to the relatively simple nature of the measurement and its

\section{OPEN ACCESS}

Edited by:

Vasko Jovanovski,

National Institute of Chemistry,

Slovenia

Reviewed by:

Dawei Pan,

Yantai Institute of Coastal Zone

Research (CAS), China

*Correspondence:

Timothy N. Lambert

tnlambe@sandia.gov

Specialty section: This article was submitted to

Electrochemistry,

a section of the journal

Frontiers in Chemistry

Received: 05 November 2021 Accepted: 14 December 2021

Published: 02 February 2022

Citation:

Wygant BR and Lambert TN (2022)

Thin Film Electrodes for Anodic

Stripping Voltammetry: A Mini-Review.

Front. Chem. 9:809535.

doi: 10.3389/fchem.2021.809535 suitability for a wide range of $\mathrm{pH}$, it has been used broadly: To measure toxic metals in the environment, characterize battery materials, and enable biological assays, among other applications. We will discuss these applications in greater detail, as well as provide perspective on future development and uses of these thin film electrodes in ASV measurements.

Keywords: anodic stripping voltammetry (ASV), metal ion analysis, batteries and energy applications, medical applications, environmental applications, metal thin film electrodes

\section{INTRODUCTION}

Anodic stripping voltammetry (ASV) is an important electrochemical technique with a history stretching back to the earliest days of electrochemistry(Zbinden, 1931). A simple technique, it allows for both the identification and quantification of electroactive species in solution at nanomolar (nM) concentrations (10s of $\mathrm{ppb}$ ) and lower and has sensitivities that are competitive with techniques like inductively coupled plasma mass spectrometry (ICP-MS)(Bard and Faulkner, 2001; Duay et al., 2017a). A detailed description of the process is available elsewhere (Ellis, 1973; Bard and Faulkner, 2001; Borrill et al., 2019), but a brief overview of the technique is provided in Scheme 1. ASV consists of two primary steps: 1) A cathodic electrodeposition to concentrate dissolved analytes at an electrode and 2) anodic stripping of the electrode to re-dissolve the species into solution. Each electrodeposited species should result in a stripping peak, where the voltage of each peak can be used to identify the species being oxidized and the peak current/integrated charge is related to the concentration of the species in solution.

ASV is traditionally performed using metallic $\mathrm{Hg}$ electrodes, generally in the form of hanging mercury drop electrodes (HMDE) or mercury film electrodes (MFE)(Ellis, 1973; Bard and Faulkner, 
I : Cathodic Pre-Concentration

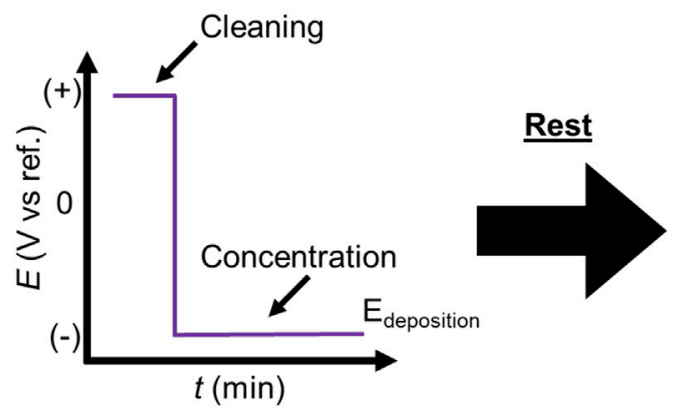

II: Anodic Stripping

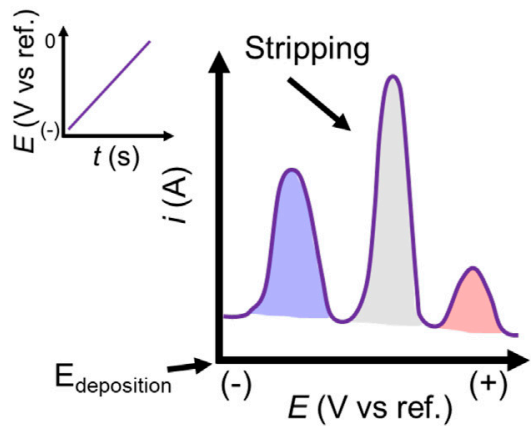

Key

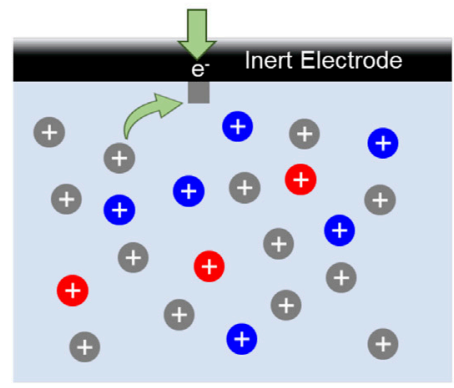

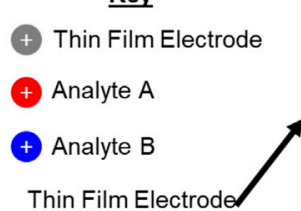

Thin Film Electrode + Analyte

Dissolved analyte and
thin film electrode precursor electrolyte solution

SCHEME 1 | Graphical depiction of a typical ASV experiment using an in situ electrode. During pre-concentration (I) an oxidizing current is first applied to clean the electrode surface, before a reducing potential sufficient to electroplate the soluble ionic metal electrode and the analyte species $\left(E_{\text {deposition}}\right)$ is applied. After a brief rest, the

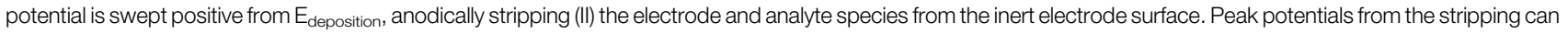
be used to identify the species, and the integrated charge under each peak can be related to the concentration of each analyte in solution.

2001). Both electrodes benefit from the high conductivity of $\mathrm{Hg}$, the ability of $\mathrm{Hg}$ to form easily-stripped amalgams with many metals, and the poor hydrogen evolution reaction (HER) kinetics on $\mathrm{Hg}$ that allow for more reductive (positive) potentials to be applied during electrodeposition. MFEs are typically preferred over HMDEs due to their lower electrode volume and thickness, both of which increase the sensitivity of the measurement(Bard and Faulkner, 2001). To achieve low electrode thickness, MFEs are typically co-deposited onto an inert electrode, typically glassy carbon, from the analyte solution after adding small quantities of $\mathrm{Hg}^{2+}$ (Bard and Faulkner, 2001; Borrill et al., 2019). Co-deposition also simplifies sample preparation and reduces the quantity of $\mathrm{Hg}$ required. Although these properties make MFEs attractive for use in ASV analyses and reduce the quantity of $\mathrm{Hg}$ needed, the inherent toxicity and significant health risks posed by $\mathrm{Hg}$ has led researchers to search for more benign alternatives.

As a result, recent work in the field has focused on replacing Hg with metals such as Bi (Wang et al., 2000; Wang et al., 2001; Li et al., 2010; Duay et al., 2017a), Sn (Czop et al., 2011; Li et al., 2012), $\mathrm{Au}$ (Bu et al., 2015; Kogan et al., 2018), and others(Tyszczuk et al., 2007; Tesarova et al., 2009; Duay et al., 2017b). Although these metals do not form the same amalgams that $\mathrm{Hg}$ does, their low toxicity and compatibility with non-acidic electrolytes has made them an exciting addition to the field. Additionally, most can be co-deposited like $\mathrm{Hg}$ to form metal thin film electrodes (MTFEs) that are very similar to more traditional
MFEs. In this mini review, we will provide a brief overview of the development and application of these MTFEs in ASV analyses and provide a perspective on future directions for such electrodes moving forward.

\section{ELECTRODE TYPES}

\section{Mercury Film Electrodes}

ASV using MFEs came into common use during the 1950s and 1960s (Ellis, 1973) as an accurate electrochemical technique for measuring metal concentration in aqueous samples(Batley and Florence, 1974). While MFEs allow for high sensitivity ASV measurements, the high concentration of analyte metal in the electrode can also result in interference from intermetallic phases. To improve the reproducibility of the measurements, MFEs are typically deposited onto glass carbon (GC) electrodes. GC electrodes are highly conductive and can be polished to a very smooth surface that is impermeable to and chemically unreactive with $\mathrm{Hg}$, allowing for the creation of a similar electrode surface over multiple experiments. Although they can be deposited from a separate $\mathrm{Hg}^{2+}$ solution and then used for ASV analysis (ex situ electrode), MFEs are frequently deposited in situ with the analyte species during the pre-concentration step. The result is a heterogeneous film tens of microns thick composed of the MFE and the analyte(s) of interest that can be readily stripped 
TABLE 1 | Overview of MTFEs metals, analytes, and sensitivities.

\begin{tabular}{|c|c|c|c|c|}
\hline Electrode metal & $\mathrm{pH}$ range & Analytes & LoD & Linear range \\
\hline \multirow[t]{5}{*}{$\mathrm{Hg}$} & $3-9$ & $\mathrm{~Pb}^{1}$ & $2.91 \mathrm{nM}$ & 20-100 nM \\
\hline & & $\mathrm{Cu}^{1}$ & $4.69 \mathrm{nM}$ & 20-100 nM \\
\hline & & $\mathrm{Cd}^{2}$ & $9.70 \mathrm{nM}$ & $10-100 \mathrm{nM}$ \\
\hline & & $\mathrm{Zn}^{2}$ & $8.06 \mathrm{nM}$ & 10-100 nM \\
\hline & & $S^{3}$ & $10.3 \mathrm{nM}$ & 20-220 nM \\
\hline \multirow[t]{7}{*}{$\mathrm{Bi}$} & $3-5,>11$ & $\mathrm{~Pb}^{4}$ (acidic) & $1.40 \mathrm{nM}$ & 0.480 nM \\
\hline & & $\mathrm{Pb}^{5}$ (basic) & $1.93 \mathrm{nM}$ & 10-290 nM \\
\hline & & $\mathrm{Cd}^{6}$ & $2.72 \mathrm{nM}$ & $9-1,335 \mathrm{nM}$ \\
\hline & & $\mathrm{Tl}^{7}$ & $0.021 \mathrm{nM}$ & 0.05-5 nM \\
\hline & & $\mathrm{Sn}^{8}$ & $16 \mathrm{nM}$ & $210-2,100 \mathrm{nM}$ \\
\hline & & $\mathrm{Pd}^{9}$ & $103 \mu \mathrm{M}$ & 188-940 $\mu \mathrm{M}$ \\
\hline & & $\mathrm{Zn}^{10}$ & $24.5 \mu \mathrm{M}$ & 46-306 $\mu \mathrm{M}$ \\
\hline \multirow[t]{3}{*}{$\mathrm{Cu}$} & $3-9$ & $\mathrm{Hg}^{11}$ & $0.50 \mu \mathrm{M}$ & $50-500 \mu \mathrm{M}$ \\
\hline & & $\mathrm{Pb}^{11}$ & $0.29 \mu \mathrm{M}$ & $24-338 \mu \mathrm{M}$ \\
\hline & & $\mathrm{Ni}^{12}$ & $3.15 \mu \mathrm{M}$ & $17-170 \mu \mathrm{M}$ \\
\hline $\mathrm{Ga}$ & $3-5$ & $\mathrm{Zn}^{13}$ & 12 nM & 50-2000 nM \\
\hline \multirow[t]{2}{*}{$\mathrm{Pb}$} & $>11$ & $\mathrm{Cu}^{14}$ & $10.5 \mu \mathrm{M}$ & $16-126 \mu \mathrm{M}$ \\
\hline & & $B i^{15}$ & $40.7 \mathrm{nM}$ & $48-480 \mathrm{nM}$ \\
\hline \multirow[t]{3}{*}{$\mathrm{Sb}$} & $2-5$ & $\mathrm{Cd}^{16}$ & $3.23 \mu \mathrm{M}$ & $118-1,246 \mu \mathrm{M}$ \\
\hline & & $\mathrm{Pb}^{16}$ & $4.34 \mu \mathrm{M}$ & 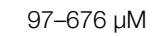 \\
\hline & & $\mathrm{Cu}^{17}$ & $15.7 \mu \mathrm{M}$ & $79-2,360 \mu \mathrm{M}$ \\
\hline \multirow[t]{3}{*}{ Sn } & $3-5$ & $\mathrm{Cd}^{18}$ & $9.79 \mu \mathrm{M}$ & $890-890 \mu \mathrm{M}$ \\
\hline & & $\mathrm{Cr}^{18}$ & $38.46 \mu \mathrm{M}$ & $192-1920 \mu \mathrm{M}$ \\
\hline & & $\mathrm{Zn}^{19}$ & $13.8 \mu \mathrm{M}$ & $0-3,059 \mu \mathrm{M}$ \\
\hline \multirow[t]{2}{*}{$\mathrm{Au}$} & $2-7.5$ & $\mathrm{Se}^{20}$ & $0.85 \mathrm{nM}$ & 5-10 nM \\
\hline & & $\mathrm{Ag}^{21}$ & $2.6 \mathrm{fM}$ & 3-337 fM \\
\hline $\mathrm{Ag}$ & $3-7$ & $\mathrm{Cr}^{22}$ & $0.1 \mu \mathrm{M}$ & $0.35-40 \mu \mathrm{M}$ \\
\hline
\end{tabular}

1 (Martiniano et al., 2013).

2 (De Oliveira et al., 2004).

3 (Huang et al., 2010).

4 (Wang et al., 2001).

5 (Li et al., 2010).

6 (Jiang et al., 2018).

7 (Rutyna and Korolczuk, 2014).

8 (Prior, 2010).

9 (Rosolina et al., 2016).

10 (Duay et al., 2017a).

11 (Jovanovski et al., 2015).

12 (Hrastnik et al., 2020).

13 (Tyszczuk et al., 2007).

14 (Duay et al., 2017b).

15 (Arnot et al., 2021).

16 (Hocevar et al., 2007).

17 (Slavec et al., 2010).

18 (Zhu et al., 2007).

19 (Czop et al., 2011).

20 (Ochab et al., 2017).

21 (Kogan et al., 2018).

22 (Stojanovic et al., 2018).

and has a high quantity of analyte to improve detection(Bard and Faulkner, 2001).

Although frequently used for testing metal concentration in aqueous samples, MFEs can also be used for ASV analysis of nonaqueous samples. For example, Marques et al. used an ex situ MFE electrode to determine the concentration of $\mathrm{Pb}$ and $\mathrm{Cu}$ in biodiesel(Martiniano et al., 2013). The researchers used 1propanol to create a microemulsion of biodiesel in nitric acid electrolyte, allowing $\mathrm{Pb}$ and $\mathrm{Cu}$ contaminants in the organic phase to be plated at the MFE. They were able to demonstrate low levels of detection (LoD) for both $\mathrm{Pb}$ and $\mathrm{Cu}(2.91$ and $4.69 \mathrm{nM}$, respectively) and showed linear concentration ranges of 20-100 nM for both species. Similar results were obtained by de Oliveira et al. who used a similar MFE to measure the $\mathrm{Zn}, \mathrm{Cu}$, $\mathrm{Pb}$, and $\mathrm{Cd}$ content of fuel ethanol generated from biological sources(De Oliveira et al., 2004). MFEs can even be used for ASV measurements of non-metallic analytes, as demonstrated by Huan and coworkers when quantifying $S^{2-}$ in synthetic wastewater(Huang et al., 2010). $\mathrm{Cd}^{2+}$ and $\mathrm{S}^{2-}$ react spontaneously in solution to form $\mathrm{CdS}$, and so by measuring the concentration of soluble $\mathrm{Cd}^{2+}$ using an ex situ MFE before and after the addition of a sample containing $\mathrm{S}^{2-}$, the quantity of $\mathrm{Cd}^{2+}$ consumed (and thus the quantity of $\mathrm{S}^{2-}$ added) could be calculated. The measurement proved to be more sensitive than competing techniques $\left(\mathrm{LoD}=10.3 \mathrm{nM} \mathrm{S}^{2-}\right.$ ) and had a linear range of 20-220 nM. Taken together, these examples showcase the utility of MFEs for ASV analysis of nontraditional analytes and from nontraditional sources.

\section{Non-Hg MTFEs}

Although MFEs are nearly ideal electrodes for ASV analysis, concerns over $\mathrm{Hg}$ toxicity and a desire to continue to improve the technique has driven the development of a thriving field of MTFEs composed of other metals. First reported by Wang et al. (Wang et al., 2000), Bi is one of the most popular non$\mathrm{Hg}$ MTFEs and can be used in a manner similar to that of both in and ex situ $\mathrm{Hg}$ analogs. Wang found that the addition of $\mathrm{Bi}^{3+}$ to the deposition solution was essential to the plating of $\mathrm{Zn}, \mathrm{Cd}$, and $\mathrm{Pb}$, and that it could be used in concert with an MFE to improve sensitivity to $\mathrm{Tl}$ and $\mathrm{Cd}$ (Wang et al., 2000). Later reports from Wang et al. also showed that, like MFEs, Bi MTFEs could be plated ex situ and used for ASV determination of $\mathrm{Pb}$ concentration(Wang et al., 2001). The electrode allowed for a $\mathrm{Pb}^{2+}$ LoD of $1.4 \mathrm{nM}$ and provided a linear range of $0-483 \mathrm{nM}$, opening the door to easily disposable Bi MTFEs for incorporation into low-cost electrodes for ASV. These early results matched or exceed similar results from MFE analyses (Wang et al., 2000), and demonstrated the utility of non-Hg MTFEs for use in ASV analysis.

Further research showed that Bi electrodes could also be used to perform ASV analysis in highly alkaline solutions(Li et al., 2010). Typical ASV analysis takes place in acidic media where the various metal ions exist in a solvated $\mathrm{M}^{+}$state, and should follow well-established mechanisms for the electrodeposition of metal in acidic media(Borrill et al., 2019). In solutions where $\mathrm{pH}>11$, however, $\mathrm{Bi}^{3+}$ can complex with the large concentration of $\mathrm{OH}^{-}$ in solution to form soluble, easily stripped/plated $\mathrm{Bi}(\mathrm{OH})^{2+}$ species(Li et al., 2010). This hydroxide complexation property is shared by other metals like $\mathrm{Pb}$ and $\mathrm{Zn}$ (Duay et al., 2017a; Duay et al., 2017b), while $\mathrm{Hg}$ forms insoluble hydrated mercury oxides that prevents the use of MFEs(Li et al., 2010). Using a Bi MTFE in $0.1 \mathrm{M} \mathrm{NaOH}$, prior work has shown it is possible to achieve an LoD of $1.93 \mathrm{nM}$ for $\mathrm{Pb}$ with a linear range of 9.6-290 nM (Li et al., 2010), matching the level of sensitivity for measurements in an acidic electrolyte and demonstrating the benefits of Bi MTFEs over MFEs for ASV analysis in alkaline conditions.

Building on this work, other metals have likewise been used as MTFEs for ASV analysis, among them Cu (Jovanovski et al., 2015; Jovanovski and Hrastnik, 2019; Hrastnik et al., 2020), Ga (Copeland et al., 1974; Tyszczuk et al., 2007; Mc Eleney et al., 


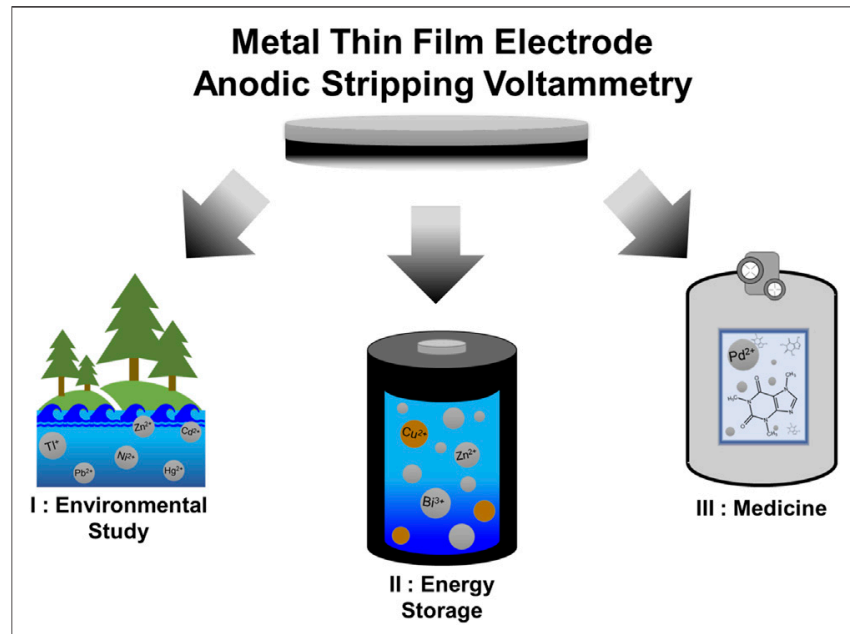

FIGURE 1 | Overview of the applications of MTFE-based ASV analysis, including I) identification and quantification of toxic metals in the environment, II) quantification of metal species in alkaline battery systems, and III) detection of catalysts and other metals in medically important systems.

2020), Pb (Duay et al., 2017b; Arnot and Lambert, 2020), Sb, (Hocevar et al., 2007; Tesarova et al., 2009; Slavec et al., 2010; Ruengpirasiri et al., 2017), Sn (Zhu et al., 2007; Czop et al., 2011; Li et al., 2012; Kokkinos et al., 2018), and precious metals like Au and $\mathrm{Ag}$ (Ochab et al., 2017; Stojanović et al., 2018; Pollok et al., 2020). A brief overview of the various MTFE metals, analytes, and sensitivities is included in Table 1. While used less frequently than $\mathrm{Hg}$ or $\mathrm{Bi}$, they are generally employed when one of these more common metals is unsuitable for the assay. For example, $\mathrm{Pb}$ allows for measurements of $\mathrm{Cu}$ and $\mathrm{Bi}$ in highly alkaline solutions (e.g., 35 wt\% KOH) (Duay et al., 2017b; Arnot and Lambert, 2020), while Ga films can be used to reduce $\mathrm{Cu}$ interference while studying Zn (Copeland et al., 1974). The general trend in the field has been one of diversification of MTFE choice to enable higher quality ASV analyses, both by using new metals and through the addition of metal additives to the electrodes. Ga is one such additive and has been used in both MFEs and Bi MTFEs to improve their $\mathrm{Zn}$ sensitivity when $\mathrm{Cu}$ also present (Tyszczuk et al., 2007). Ga reacts readily and selectively with $\mathrm{Zn}$ during preconcentration to form a single Ga-Zn species, preventing the formation of multiple $\mathrm{Cu}-\mathrm{Zn}$ intermetallic species and simplifying the ASV assay for Zn (Copeland et al., 1974).

\section{Experimental Considerations for ASV}

As there are many metals suitable for use as ASV MTFEs, care must be taken when choosing an electrode material. First and foremost, regardless of the metal used to create the MTFE it is important to consider complications inherent to the use of thin film electrodes. These include, but are not limited to, the cleaning of the substrate/electrode surface (before electrode deposition and/or each experiment), unavoidable fouling of electrode from contaminant species in solution, the solubility of metallic species in solution, film-to-film variations of in situ MTFEs, and proper calibration of the assay prior to measurements. The last two points are of particular importance, as the low quantities of metal used to create the MTFEs could easily result in uneven films, and therefore electrochemical responses, that must be taken into account. For a more detailed discussion of these topics, we recommend the tutorial review written by Borrill et al. (Borrill et al., 2019) After these general points, the next consideration is the $\mathrm{pH}$ of the solution the assay will be performed in. If there is sufficient electrolyte concentration, regardless of $\mathrm{pH}$, ASV analysis can be performed in the native sample solution with minimal preparation, unlike inductively coupled plasma mass spectrometry (ICP-MS) (Duay et al., 2017a). Sb MTFEs have been shown to be effective $\mathrm{Hg}$ replacements in highly acidic media $(\mathrm{pH}$ <2) (Tesarova et al., 2009), but ASV is frequently performed in moderately acidic solutions ( $\mathrm{pH} 3-5)$ to prevent hydrolysis by the metal ions in solution. Such conditions are suitable for traditional MFEs, as well as Bi, Cu, Ga, Sb, and Sn MTFEs (Wang et al., 2000; Tyszczuk et al., 2007; Tesarova et al., 2009; Li et al., 2012; Jovanovski et al., 2015). For solutions of $\mathrm{pH} 7-9, \mathrm{Hg}$ and $\mathrm{Cu}$ are commonly employed (Guell et al., 2008; Hrastnik et al., 2020). For highly alkaline solutions $(\mathrm{pH}>11)$, both $\mathrm{Bi}$ and $\mathrm{Pb}$ form soluble hydroxide complexes and have wide electrochemical windows that make them ideal MTFEs (Li et al., 2010; Arnot and Lambert, 2020).

After $\mathrm{pH}$, one should also consider the chemical interactions of the species of interest with the electrode and other species in solution. $\mathrm{Bi}$ and $\mathrm{Hg}$ have wide electrochemical windows and good plating behavior that make them ideal electrodes for many other metals (Wang et al., 2000). Even for Bi and Hg MTFEs, some analyte species may deposit multiple intermetallic phases when plating or suffer from poor plating efficiency, complicating the assay and requiring additive species to reduce the impact. As mentioned before, Ga prevents the formation of undesired intermetallic phases in the presence of $\mathrm{Cu}$ (Copeland et al., 1974), while cetyltrimethylammonium bromide (CTAB) has been found to reduce the interference of $\mathrm{Pb}$ on $\mathrm{Sn}$ assays (Prior, 2010). With regard to plating efficiency, a combination of $\mathrm{Pb}$ and $\mathrm{Cd}$ additives has been shown to improve the plating of both $\mathrm{Zn}$ and Pd using Bi MTFEs (Rosolina et al., 2016; Duay et al., 2017a). Based on these results, we speculate that there may be a wide range of metals that are suitable for use as additives to ASV MTFEs.

\section{REVIEW OF APPLICATIONS}

The relative simplicity and broad applicability of MTFEs and ASV assays has led to their use in a wide range of fields, including the monitoring of various metals in the environment (Kefala, 2003; Lee et al., 2017; Lu et al., 2018), the quantification of soluble metal species in battery electrolytes (Duay et al., 2017a; Duay et al., 2017b; Arnot and Lambert, 2020), and even measuring the quantity of biomolecules in blood serum (Pollok et al., 2020). Below, we have provided an overview of some recent applications of MTFEs and ASV in these fields and others (Figure 1).

\section{Environmental Studies}

Because ASV requires significantly less sample preparation and equipment to accurately quantify metals in a wide range of 
sample media, it is frequently used to detect and measure the concentration of various heavy metals $(\mathrm{Pb}, \mathrm{Cd}, \mathrm{Zn}, \mathrm{Tl}, \mathrm{Ni}$, etc.) in the environment (Lu et al., 2018). As an example, Rutyna et al. used an in situ Bi MTFE to measure the concentration of $\mathrm{Tl}$ in samples of lake water, achieving an LoD of $0.021 \mathrm{nM}$ for $\mathrm{Tl}$ with a linear range of $0.05-5 \mathrm{nM}$ (Rutyna and Korolczuk, 2014). This level of accuracy required a second preconcentration step be added to the procedure, significantly concentrating the $\mathrm{Tl}$ present in the solution and allowing for detection at ultratrace concentrations, even in complex media.

Similarly, Jian et al. showed that a Bi MTFE deposited onto $\mathrm{GaN}$ was able to achieve a $2.72 \mathrm{nM} \mathrm{LoD}$ for Cd with a linear range of 8.9-1,334.5 nM (Jiang et al., 2018). Here, GaN provided an inert, highly conductive substrate upon which the Bi MTFE could be deposited during the ASV assay, and the composite electrode showed high Cd recovery efficiency from several complex matrixes including natural waters and others. As a final example, Lee et al. used a 3D printed stainless steel electrode to create an ex situ Bi MTFE for ASV measurements of Cd and Pb (Lee et al., 2017). The researchers demonstrated that custom electrodes could be created and successfully applied to electrochemical measurements, achieving LoDs of 17 and $83 \mathrm{nM}$ for $\mathrm{Pb}$ and $\mathrm{Cd}$, respectively, and linear ranges between 200 and 3,000 nM. While just a few examples, they demonstrate the use of MTFEs and ASV in detecting a range of toxic metals in environmentally relevant sample matrixes.

\section{Batteries and Energy Applications}

ASV has also been useful in the study and characterization of alkaline battery systems, recently in the analysis of metal ion diffusion through polymer separators of use in $\mathrm{Zn} / \mathrm{MnO}_{2}$ batteries (Duay et al., 2017a; Duay et al., 2018; Kolesnichenko et al., 2020; Arnot et al., 2021). During electrochemical cycling, soluble $\mathrm{Zn}$ species generated at the $\mathrm{Zn}$ anode can react with the $\mathrm{MnO}_{2}$ cathode, irreversibly forming $\mathrm{ZnMn}_{2} \mathrm{O}_{4}$ and decreasing the capacity of the cell (Duay et al., 2017a). In addition to preventing electrical short circuits, Zn-impermeable separators can prevent this reaction, but identifying promising polymers through traditional ICP-MS crossover experiments is time and processing intensive. Recently, our group has shown that ASV using MTFEs can replace ICP-MS and significantly simplify measurements of $\mathrm{Zn}$ permeability, and have used the assay to characterize several commercial and custom battery separators (Duay et al., 2017a; Kolesnichenko et al., 2020). Using in situ Bi MTFEs with $\mathrm{Pb}$ and $\mathrm{Cd}$ additives, Duay et al. achieved an LoD of $24.5 \mu \mathrm{M}$ for $\mathrm{Zn}$ in a $35 \mathrm{wt} \%$ solution of $\mathrm{KOH}$, with a linear response range from 45.8-305.9 $\mu \mathrm{M}$ (Duay et al., 2017a). This result was similar to the LoD of ICP-MS $(115 \mu \mathrm{M})$ in the same $\mathrm{KOH}$ solution, but could be performed in the concentrated alkaline electrolyte, whereas the ICP-MS required significant dilution and neutralization.

In subsequent studies, our group also demonstrated that in situ $\mathrm{Pb}$ MTFEs could be used to measure diffusion of $\mathrm{Cu}$ and $\mathrm{Bi}$ through separators; both are promising additives for $\mathrm{Zn}$ alkaline batteries. Again working directly in the $35 \mathrm{wt} \% \mathrm{KOH}$ solution used in alkaline batteries, a Pb MTFE achieved LoDs of $10.5 \mu \mathrm{M}$ and $40.7 \mathrm{nM}$ for $\mathrm{Cu}$ and $\mathrm{Bi}$, respectively, with linear responses between 15.7-125.9 $\mu \mathrm{M}$ for $\mathrm{Cu}$ and $47.8-478.5 \mathrm{nM}$ for Bi (Duay et al., 2017b; Arnot and Lambert, 2020). Although the use of MTFE-based ASV analysis in battery research is in its infancy, we believe these results indicate it has great promise and will discuss them at more length in the Future Outlooks.

\section{Medical Applications}

The final application of MTFEs for ASV pertains to medical assays, where the sensitivity and tolerance of these electrodes for complex matrices makes them ideal for detecting medically relevant species. As an example, Rosolina et al. used an in situ Bi MTFE to quantify Pd levels in simulated pharmaceutical matrixes(Rosolina et al., 2016). Possessing some toxicity, Pd is used to catalyze many organic reactions during drug synthesis and trace quantities can be left in the final consumer product. Without requiring time-consuming digestion steps, the authors demonstrated an LoD of $103 \mu \mathrm{M}$ in an aqueous solution containing caffeine, with a linear range of $188-939.4 \mu \mathrm{M}$. Interestingly, the authors noted that $\mathrm{Cd}$ and $\mathrm{Pb}$ improved the sensitivity of the measurement for $\mathrm{Pd}$ in a manner analogous to that reported by Duay et al.(Duay et al., 2017a) This result suggests that these species may be important in achieving low LoDs with Bi MTFEs.

MTFEs have also been used to quantify organic species like quinolones and peptides using ASV (Kergaravat et al., 2018; Pollok et al., 2020). Kergaravat et al. used an ex situ Bi MTFE to quantify two separate quinolones in both buffer solutions and cladoceran crustaceans culture media; they reported an LoD of $1 \mathrm{nM}$ for moxifloxacin and other quinolones with a linear range of 2.99-87.2 nM (Kergaravat et al., 2018). This allowed the researchers to use ASV to show a correlation between degradation of the molecule and the death of the crustaceans, indicating that similar processes may occur in nature. To measure complex heart-failure related peptides, the Crooks group has coupled Ag MTFEs with peptide-specific antibodies for N-terminal prohormone brain natriuretic peptide (NTproBNP) (Kogan et al., 2018; Pollok et al., 2020). During the assay, sequential stripping of both an ex situ Au MTFE and galvanic exchange to produce an in situ Ag MTFE that can be used to determine the quantity of the peptide in solution. The Ag nanoparticles are bound to peptide-specific antibodies, creating the correlation between the quantity of Ag measured during ASV and the quantity of peptide present in the sample. Using this assay, Pollok et al. achieved an LoD near $0.58 \mathrm{nM}$ and a linear range of $0.58-2.33 \mathrm{nM}$ (Pollok et al., 2020). Although this sensitivity is currently insufficient for clinical application, the whole assay can be performed on a paper-based device that promises to reduce the costs associated and complex equipment typically associated with these types of assays.

The above examples, while only a small selection of the many applied MTFEs in literature, represent a variety of applications where MTFE-based ASV is found. They showcase the sensitive measurements and chemical selectivity that MTFEs bring to electrochemical analysis and the diverse applications that such relatively simple systems can be used in, making a compelling case for the inclusion of MTFEs and ASV in the standard analytical toolbox. 


\section{FUTURE OUTLOOK}

Although the previous examples show how mature MTFEs and ASV have become, better characterization of the MTFEs used to perform ASV analysis is still needed. MTFEs are frequently electrodeposited and stripped without ever being removed from solution, precluding any physical or chemical characterization with techniques like scanning electron microscopy (SEM) or X-ray photoelectron spectroscopy (XPS). Doing so means that while great care is frequently taken to optimize the deposition parameters of an assay (MTFE precursor concentration, analyte concentration, deposition potential, etc.), we do not know how these optimizations relate to the morphology or chemistry of the resulting electrode surface.

Demonstrating the importance of these properties, Rajamani et al. performed a systematic study of Bi electrodeposition using different deposition conditions and solutions additives to determine how each impacted the final morphology, chemistry, and physical properties of the MTFE (Rajamani et al., 2016). They found that both additives and deposition conditions can impact the properties of the deposited MTFE, and that small, smooth $\mathrm{Bi}$ crystallites show better $\mathrm{Pb}$ sensitivity than higher surface area crystallites. Studies like this illustrate that a holistic understanding of MTFEs can produce better electrodes for ASV analysis and reinforce the need for more such research.

Beyond electrode characterization, additional work developing non-toxic MTFEs would also be of benefit. While $\mathrm{Bi}$ is now widely recognized as a suitable replacement for $\mathrm{Hg}$, recent work has shown that the addition of toxic metals like $\mathrm{Pb}$ and Cd can improve the sensitivity of these otherwise non-toxic MTFEs (Rosolina et al., 2016; Duay et al., 2017a). With work, lesstoxic alternatives like $\mathrm{Ga}$ or $\mathrm{Sn}$ may be able to replace these important additives. Such work may also lead to MTFEs with improved ASV performance in neutral and alkaline electrolytes, opening doors to new applications for the technique. New fields of study could include electrochemical fuel cells, where electrocatalytically active metals like Pt are known to dissolve and redeposit in the alkaline electrolytes (Deng et al., 2019). As in the $\mathrm{Zn}$ assays performed by our group to evaluate alkaline battery separators (Duay et al., 2017a; Duay et al., 2018; Kolesnichenko et al., 2020; Arnot et al., 2021), Sn or Bi MTFEs may be useful in quickly and simply quantifying this dissolution. Alternatively, MTFE-based ASV analysis like that demonstrated by Crooks and coworkers could find expanded use in electrochemical assays of other biomolecules. ASV analysis is highly sensitive and relatively simple to perform, making it an exciting option for inexpensive, portable assays of many biologically important species. Finally, recent work has demonstrated that multi-metal or alloy MTFE electrodes show improved ASV performance when compared to single metal electrodes (Rosolina et al., 2016; Duay et al., 2017a; Valera et al., 2018). These studies and others demonstrate that metal alloys can exhibit increased HER overpotentials and improved deposition/stripping behavior when compared to electrodes composed of a single metal, but additional work is needed to optimize and characterize these electrodes. Determining how the addition of a specific metal impacts electrode performance will be important, as well as whether the resulting MTFE is better classified as a bimetallic electrode or an alloy, will allow for more directed development of these MTFEs in the future.

\section{CONCLUSION}

MTFEs offer many benefits for ASV analysis over more traditional HMDE and bulk electrodes. MTFEs can be deposited in situ along with the analyte species, producing highly concentrated electrode films with excellent sensitivity over broad concentration ranges. Many metals can be used to create MTFEs, including both the traditional (but toxic) $\mathrm{Hg}$ and less toxic alternatives like $\mathrm{Bi}$ or $\mathrm{Sn}$. This breadth allows for the tailoring of the MTFE for a particular assay, producing electrochemically distinct bimetallic alloys with the species of interest, even in the presence of other species of interest. Coupled with the relative ease of ASV sample preparation, these electrodes allow for higher throughput analysis of samples ranging from natural water to blood serum. MTFE-based ASV assays have been applied to many different systems in the recent past, and should remain a sensitive and useful tool for chemical analysis in these, and other, applications moving forward.

\section{AUTHOR CONTRIBUTIONS}

BW and TL contributed to conception and design of the study. BW wrote the main draft of the manuscript. Both authors contributed to manuscript revision, read, and approved the submitted version.

\section{FUNDING}

This work was supported by the U.S. Department of Energy Office of Electricity. Sandia National Laboratories is a multimission laboratory managed and operated by National Technology and Engineering Solutions of Sandia, LLC, a wholly owned subsidiary of Honeywell International, Inc., for the U.S. Department of Energy's National Nuclear Security Administration under contract DE-NA0003525-NA.

\section{ACKNOWLEDGMENTS}

Imre Gyuk, Director of Energy Storage Research at the U.S. Department of Energy Office of Electricity, is thanked for his financial support of this project. 


\section{REFERENCES}

Arnot, D. J., and Lambert, T. N. (2020). Bismuth Detection in Alkaline Electrolyte via Anodic Stripping Voltammetry for Battery Separator Evaluation. Electroanalysis 33, 797-803. doi:10.1002/elan.202060412

Arnot, D. J., Lim, M. B., Bell, N. S., Schorr, N. B., Hill, R. C., Meyer, A., et al. (2021). High Depth-of-Discharge Zinc Rechargeability Enabled by a Self-Assembled Polymeric Coating. Adv. Energ. Mater. 11. doi:10.1002/aenm.202101594

Bard, A. J., and Faulkner, L. R. (2001). Electrochemical Methods: Fundamentals and Applications.

Batley, G. E., and Florence, T. M. (1974). An Evaluation and Comparison of Some Techniques of Anodic Stripping Voltammetry. J. Electroanalytical Chem. Interfacial Electrochemistry 55, 23-43. doi:10.1016/s0022-0728(74) 80469-9

Borrill, A. J., Reily, N. E., and Macpherson, J. V. (2019). Addressing the Practicalities of Anodic Stripping Voltammetry for Heavy Metal Detection: a Tutorial Review. Analyst 144, 6834-6849. doi:10.1039/c9an01437c

Bu, L., Gu, T., Ma, Y., Chen, C., Tan, Y., Xie, Q., et al. (2015). Enhanced Cathodic Preconcentration of $\mathrm{As}(0)$ at $\mathrm{Au}$ and Pt Electrodes for Anodic Stripping Voltammetry Analysis of $\mathrm{As}(\mathrm{III})$ and $\mathrm{As}(\mathrm{V})$. J. Phys. Chem. C 119, 11400-11409. doi:10.1021/acs.jpcc.5b01435

Copeland, T. R., Osteryoung, R. A., and Skogerboe, R. K. (1974). Elimination of Copper-Zinc Intermetallic Interferences in Anodic Stripping Voltammetry. Anal. Chem. 46, 2093-2097. doi:10.1021/ac60350a036

Czop, E., Economou, A., and Bobrowski, A. (2011). A Study of In Situ Plated TinFilm Electrodes for the Determination of Trace Metals by Means of SquareWave Anodic Stripping Voltammetry. Electrochimica Acta 56, 2206-2212. doi:10.1016/j.electacta.2010.12.017

De Oliveira, M. F., Saczk, A. A., Okumura, L. L., Fernandes, A. P., De Moraes, M., and Stradiotto, N. R. (2004). Simultaneous Determination of Zinc, Copper, lead, and Cadmium in Fuel Ethanol by Anodic Stripping Voltammetry Using a Glassy Carbon-Mercury-Film Electrode. Anal. Bioanal. Chem. 380, 135-140. doi:10.1007/s00216-004-2733-8

Deng, X., Galli, F., and Koper, M. T. M. (2019). In Situ AFM Imaging of Platinum Electrode Surface during Oxidation-Reduction Cycles in Alkaline Electrolyte. ACS Appl. Energ. Mater. 3, 597-602. doi:10.1021/acsaem.9b01700

Duay, J., Kelly, M., and Lambert, T. N. (2018). Evaluation of a Ceramic Separator for Use in Rechargeable Alkaline $\mathrm{Zn} / \mathrm{MnO} 2$ Batteries. J. Power Sourc. 395, 430-438. doi:10.1016/j.jpowsour.2018.05.072

Duay, J., Lambert, T. N., and Aidun, R. (2017a). Stripping Voltammetry for theReal TimeDetermination of Zinc Membrane Diffusion Coefficients in High pH: Towards Rapid Screening of Alkaline Battery Separators. Electroanalysis 29, 2261-2267. doi:10.1002/elan.201700337

Duay, J., Ortiz-Santiago, J. E., and Lambert, T. N. (2017b). Copper Sensing in Alkaline Electrolyte Using Anodic Stripping Voltammetry by Means of a Lead Mediator. Electroanalysis 29, 2685-2688. doi:10.1002/elan.201700526

Ellis, W. D. (1973). Anodic Stripping Voltammetry. J. Chem. Educ. 50, A131. doi:10.1021/ed050pa131

Güell, R., Aragay, G., Fontàs, C., Anticó, E., and Merkoçi, A. (2008). Sensitive and Stable Monitoring of lead and Cadmium in Seawater Using Screen-Printed Electrode and Electrochemical Stripping Analysis. Analytica Chim. Acta 627, 219-224. doi:10.1016/j.aca.2008.08.017

Hocevar, S. B., Švancara, I., Ogorevc, B., and Vytřas, K. (2007). Antimony Film Electrode for Electrochemical Stripping Analysis. Anal. Chem. 79, 8639-8643. doi: $10.1021 / \mathrm{ac} 070478 \mathrm{~m}$

Hrastnik, N. I., Jovanovski, V., and Hočevar, S. B. (2020). In-situ Prepared Copper Film Electrode for Adsorptive Stripping Voltammetric Detection of Trace Ni(II). Sensors Actuators B: Chem. 307. doi:10.1016/j.snb.2019.127637

Huang, D., Xu, B., Tang, J., Luo, J., Chen, L., Yang, L., et al. (2010). Indirect Determination of Sulfide Ions in Water Samples at Trace Level by Anodic Stripping Voltammetry Using Mercury Film Electrode. Anal. Methods 2, 154-158. doi:10.1039/b9ay00183b

Jiang, Q.-M., Zhang, M.-R., Hou, F., Wang, Z.-G., Zhang, S.-H., Chen, Y., et al. (2018). In Situ bismuth-modified Gallium Nitride Electrode for Sensitive Determination of Cadmium (II) with High Repeatability. J. Electroanalytical Chem. 809, 105-110. doi:10.1016/j.jelechem.2017.12.056
Jovanovski, V., Hrastnik, N. I., and Hočevar, S. B. (2015). Copper Film Electrode for Anodic Stripping Voltammetric Determination of Trace Mercury and lead. Electrochemistry Commun. 57, 1-4. doi:10.1016/j.elecom.2015.04.018

Jovanovski, V., and Hrastnik, N. I. (2019). Insights into the Anodic Stripping Voltammetric Behaviour of Copper Film Electrodes for Determination of Trace Mercury. Microchemical J. 146, 895-899. doi:10.1016/j.microc.2019.02.027

Kefala, G. (2003). A Study of Bismuth-Film Electrodes for the Detection of Trace Metals by Anodic Stripping Voltammetry and Their Application to the Determination of $\mathrm{Pb}$ and $\mathrm{Zn}$ in Tapwater and Human Hair. Talanta 61, 603-610. doi:10.1016/s0039-9140(03)00350-3

Kergaravat, S. V., Gagneten, A. M., and Hernandez, S. R. (2018). Development of an Electrochemical Method for the Detection of Quinolones: Application to Cladoceran Ecotoxicity Studies. Microchemical J. 141, 279-286. doi:10.1016/ j.microc.2018.05.039

Kogan, M. R., Pollok, N. E., and Crooks, R. M. (2018). Detection of Silver Nanoparticles by Electrochemically Activated Galvanic Exchange. Langmuir 34, 15719-15726. doi:10.1021/acs.langmuir.8b03325

Kokkinos, C., Economou, A., and Giokas, D. (2018). Paper-based Device with a Sputtered Tin-Film Electrode for the Voltammetric Determination of Cd(II) and $\mathrm{Zn}(\mathrm{II})$. Sensors Actuators B: Chem. 260, 223-226. doi:10.1016/ j.snb.2017.12.182

Kolesnichenko, I. V., Arnot, D. J., Lim, M. B., Yadav, G. G., Nyce, M., Huang, J., et al. (2020). Zincate-Blocking-Functionalized Polysulfone Separators for Secondary Zn-MnO2 Batteries. ACS Appl. Mater. Inter. 12, 50406-50417. doi:10.1021/acsami.0c14143

Lee, K. Y., Ambrosi, A., and Pumera, M. (2017). 3D-printed Metal Electrodes for Heavy Metals Detection by Anodic Stripping Voltammetry. Electroanalysis 29, 2444-2453. doi:10.1002/elan.201700388

Li, B. L., Wu, Z. L., Xiong, C. H., Luo, H. Q., and Li, N. B. (2012). Anodic Stripping Voltammetric Measurement of Trace Cadmium at Tin-Coated Carbon Paste Electrode. Talanta 88, 707-710. doi:10.1016/j.talanta.2011.11.070

Li, D., Jia, J., and Wang, J. (2010). A Study on the Electroanalytical Performance of a Bismuth Film-Coated and Nafion-Coated Glassy Carbon Electrode in Alkaline Solutions. Microchim Acta 169, 221-225. doi:10.1007/s00604-0100337-x

Lu, Y., Liang, X., Niyungeko, C., Zhou, J., Xu, J., and Tian, G. (2018). A Review of the Identification and Detection of Heavy Metal Ions in the Environment by Voltammetry. Talanta 178, 324-338. doi:10.1016/j.talanta.2017.08.033

Martiniano, L. C., Abrantes, V. R., Neto, S. Y., Marques, E. P., Fonseca, T. C. O., Paim, L. L., et al. (2013). Direct Simultaneous Determination of $\mathrm{Pb}(\mathrm{II})$ and $\mathrm{Cu}(\mathrm{II})$ in Biodiesel by Anodic Stripping Voltammetry at a Mercury-Film Electrode Using Microemulsions. Fuel 103, 1164-1167. doi:10.1016/ j.fuel.2012.07.002

Mc Eleney, C., Alves, S., and Mc Crudden, D. (2020). Novel Determination of Cd and $\mathrm{Zn}$ in Soil Extract by Sequential Application of Bismuth and Gallium Thin Films at a Modified Screen-Printed Carbon Electrode. Analytica Chim. Acta 1137, 94-102. doi:10.1016/j.aca.2020.08.056

Ochab, M., Gęca, I., and Korolczuk, M. (2017). Determination of Trace Se(IV) by Anodic Stripping Voltammetry Following Double Deposition and Stripping Steps. Talanta 165, 364-368. doi:10.1016/j.talanta.2016.12.034

Pollok, N. E., Rabin, C., Walgama, C. T., Smith, L., Richards, I., and Crooks, R. M. (2020). Electrochemical Detection of NT-proBNP Using a Metalloimmunoassay on a Paper Electrode Platform. ACS Sens. 5, 853-860. doi:10.1021/acssensors.0c00167

Prior, C. (2010). Anodic Stripping Voltammetry of Tin at the Bismuth Film Electrode Using Cetyltrimethylammonium Bromide. Electroanalysis 22, 1446-1454. doi:10.1002/elan.200970004

Rajamani, A. R., Jothi, S., Kumar, M. D., Srikaanth, S., Singh, M. K., Otero-Irurueta, G., et al. (2016). Effects of Additives on Kinetics, Morphologies and LeadSensing Property of Electrodeposited Bismuth Films. J. Phys. Chem. C 120, 22398-22406. doi:10.1021/acs.jpcc.6b06924

Rosolina, S. M., Chambers, J. Q., and Xue, Z.-L. (2016). Direct Analysis of Palladium in Active Pharmaceutical Ingredients by Anodic Stripping Voltammetry. Analytica Chim. Acta 914, 47-52. doi:10.1016/j.aca.2016.02.007

Ruengpirasiri, P., Punrat, E., Chailapakul, O., and Chuanuwatanakul, S. (2017) Graphene Oxide-Modified Electrode Coated Within-situAntimony Film for the Simultaneous Determination of Heavy Metals by Sequential Injection-Anodic 
Stripping Voltammetry. Electroanalysis 29, 1022-1030. doi:10.1002/ elan. 201600568

Rutyna, I., and Korolczuk, M. (2014). Determination of Ultratrace Thallium(I) by Anodic Stripping Voltammetry at Bismuth Film Electrodes Following Double Deposition and Stripping Steps. Electroanalysis 26, 2639-2643. doi:10.1002/elan.201400483

Slavec, M., Hocevar, S. B., Baldrianova, L., Tesarova, E., Svancara, I., Ogorevc, B., et al. (2010). Antimony Film Microelectrode for Anodic Stripping Measurement of Cadmium(II), Lead(II) and Copper(II). Electroanalysis 22, 1617-1622. doi:10.1002/elan.200900583

Stojanović, Z., Koudelkova, Z., Sedlackova, E., Hynek, D., Richtera, L., and Adam, V. (2018). Determination of Chromium(vi) by Anodic Stripping Voltammetry Using a Silver-Plated Glassy Carbon Electrode. Anal. Methods 10, 2917-2923.

Tesarova, E., Baldrianova, L., Hocevar, S. B., Svancara, I., Vytras, K., and Ogorevc, B. (2009). Anodic Stripping Voltammetric Measurement of Trace Heavy Metals at Antimony Film Carbon Paste Electrode. Electrochimica Acta 54, 1506-1510. doi:10.1016/j.electacta.2008.09.030

Tyszczuk, K., Korolczuk, M., and Grabarczyk, M. (2007). Application of Gallium Film Electrode for Elimination of Copper Interference in Anodic Stripping Voltammetry of Zinc. Talanta 71, 2098-2101. doi:10.1016/j.talanta.2006.09.021

Valera, D., Sánchez, M., Domínguez, J. R., Alvarado, J., Espinoza-Montero, P. J., Carrera, P., et al. (2018). Electrochemical Determination of lead in Human Blood Serum and Urine by Anodic Stripping Voltammetry Using Glassy Carbon Electrodes Covered with Ag-Hg and Ag-Bi Bimetallic Nanoparticles. Anal. Methods 10, 4114-4121. doi:10.1039/c8ay01314d

Wang, J., Lu, J., Hocevar, S. B., Farias, P. A. M., and Ogorevc, B. (2000). BismuthCoated Carbon Electrodes for Anodic Stripping Voltammetry. Anal. Chem. 72, 3218-3222. doi:10.1021/ac000108x

Wang, J., Lu, J., Hocevar, S. B., and Ogorevc, B. (2001). Bismuth-Coated Screen-Printed Electrodes for Stripping Voltammetric Measurements of Trace Lead. Electroanalysis 13, 13-16. doi:10.1002/1521-4109(200101)13:1<13:aid-elan13>3.0.co;2-f
Zbinden, C. (1931). Nouvelle méthode de microdétermination de l'ion cuivre. Bull. Soc. Chim. Biol. 13, 35-38.

Zhu, W., Li, N., and Luo, H. (2007). Simultaneous Determination of Chromium(III) and Cadmium(II) by Differential Pulse Anodic Stripping Voltammetry on a Stannum Film Electrode. Talanta 72, 1733-1737. doi:10.1016/j.talanta.2007.04.055

Conflict of Interest: BW and TL were employed by the company Sandia National Laboratories. Sandia National Laboratories is a multi-mission laboratory managed and operated by National Technology and Engineering Solutions of Sandia, LLC, a wholly owned subsidiary of Honeywell International, Inc., for the U.S. Department of Energy's National Nuclear Security Administration under contract DENA0003525-NA.

The authors declare that the research was conducted in the absence of any other commercial or financial relationships that could be construed as a potential conflict of interest.

Publisher's Note: All claims expressed in this article are solely those of the authors and do not necessarily represent those of their affiliated organizations, or those of the publisher, the editors and the reviewers. Any product that may be evaluated in this article, or claim that may be made by its manufacturer, is not guaranteed or endorsed by the publisher.

Copyright $\odot 2022$ Wygant and Lambert. This is an open-access article distributed under the terms of the Creative Commons Attribution License (CC BY). The use, distribution or reproduction in other forums is permitted, provided the original author(s) and the copyright owner(s) are credited and that the original publication in this journal is cited, in accordance with accepted academic practice. No use, distribution or reproduction is permitted which does not comply with these terms. 